\title{
Integrated approach on solar drying, pilot convective drying and microstructural changes
}

\author{
Inês N. Ramos, Teresa R.S. Brandão, Cristina L.M. Silva * \\ Universidade Católica Portuguesa, Escola Superior de Biotecnologia Rua Dr. António Bernardino de Almeida, 4200-072 Porto, Portugal
}

Keywords: Drying; Solar drying; Microstructure; Mass transfer; Heat transfer

\begin{abstract}
Solar drying of foods is an old technique, still used nowadays. Nevertheless, the mathematical approach of the complex phenomena involved is not completely integrated. Drawbacks appear in modelling heat transport, specially related to the huge variability of meteorological factors. The great dependence of the heat and mass transfer model parameters on water content is also frequently forgotten. Macroscopic changes (e.g. shrinkage) that occur during drying processes, are usually not considered in mass transfer equations, also affecting the predictive ability of the models.

The objective of this work was to develop the mathematical basis and considerations for integrating heat and mass transfer phenomena, taking into consideration macroscopic changes and their correlation to changes at microscopic level (e.g. cellular shrinkage), that might occur during solar drying of grapes.
\end{abstract}

\section{Introduction}

Nowadays, there are still a large number of agricultural products dried using solar energy (e.g. fruits, vegetables, flowers, aromatic herbs and medical plants). Although being an ancient technique, comprehensive reviews on solar drying only appeared recently. One of the first overall studies on solar drying was done by Bolin and Salunkhe (1982), concerning equipment, techniques and dried foods quality.

Drying is a complex phenomenon, whose mechanisms are not yet entirely understood. In the case of solar drying, the complexity becomes even more noteworthy due to changes of meteorological factors during the entire process. Solar radiation intensity has also a

* Corresponding author. Tel.: +351 22 5580058; fax: +351 22 5090351.

E-mail address: crislui@esb.ucp.pt (C.L.M. Silva). great variability (Mühlbauer \& Esper, 1999), changing from season to season, according to the weather conditions and with the hour of the day.

Mathematical modelling is essential to predict and simulate the drying behaviour. It is also an important tool in dryers design, contributing for a better understanding of the drying mechanism. Similarly to any other process, models that describe the drying phenomena can be developed on a mechanistic or empirical basis. In general, mechanistic models are more complex, but allow accurate predictions. Empirical models are much simple, but sometimes are just appropriate for practical uses such as dryers design (Mulet, 1994). Some authors consider that simpler models are a better option (Madamba, Driscoll, \& Buckle, 1996). Nevertheless, the choice should be a balance of the advantages and disadvantages, also depending on the final purpose.

Modelling solar drying processes is based on equations that rule heat and mass transfer phenomena, analogous to those involved in convective drying. The solar 


\begin{tabular}{|c|c|c|c|}
\hline \multicolumn{4}{|c|}{ Nomenclature } \\
\hline$A_{\mathrm{p}}$ & projected area $\left(\mathrm{m}^{2}\right)$ & $q_{\mathrm{s}}$ & incident solar energy $\left(\mathrm{J} \mathrm{s}^{-1}\right)$ \\
\hline$A_{\mathrm{s}}$ & surface area $\left(\mathrm{m}^{2}\right)$ & $r$ & radial direction $(\mathrm{m})$ \\
\hline$a_{\mathrm{w}}$ & water activity & $r_{\mathrm{r}}$ & external radius of the sphere $(\mathrm{m})$ \\
\hline$a, b, c$ & $\begin{array}{l}\text { constants of the model that relates } D_{\text {eff }} \text { with } \\
\text { water content (Eq. (4)) }\end{array}$ & $\begin{array}{l}t \\
T\end{array}$ & $\begin{array}{l}\text { time }(\mathrm{s}) \\
\text { absolute temperature }(\mathrm{K})\end{array}$ \\
\hline$C$ & Guggenheim constant (Eq. (7)) & $R$ & ideal gas constant $\left(\mathrm{J} \mathrm{mol}^{-1} \mathrm{~K}^{-1}\right)$ \\
\hline$C_{0}$ & $\begin{array}{l}\text { pre-exponential factor of the model that cor- } \\
\text { related the Guggenheim constant to tempera- } \\
\text { ture (Eq. (8)) }\end{array}$ & $\begin{array}{l}\mathrm{RHa} \\
V \\
x, y, z\end{array}$ & $\begin{array}{l}\text { air relative humidity }(\%) \\
\text { volume }\left(\mathrm{m}^{3}\right) \\
\text { space coordinates }(\mathrm{m})\end{array}$ \\
\hline$C_{\mathrm{p}}$ & $\begin{array}{l}\text { specific heat capacity of the drying product } \\
\left(\mathrm{J} \mathrm{kg}^{-1} \mathrm{~K}^{-1}\right)\end{array}$ & $X$ & $\begin{array}{l}\text { water content in dry basis }\left(\mathrm{kg}_{\text {water }}\right. \\
\left.\mathrm{kg}_{\text {dry }} \text { matter }^{-1}\right)\end{array}$ \\
\hline$d, e, f$ & $\begin{array}{l}\text { constants of the model that relates } D_{\text {eff }} \text { with } \\
\text { water content and temperature (Eq. (5)) }\end{array}$ & $\bar{X}$ & $\begin{array}{l}\text { average water content in dry basis }\left(\mathrm{kg}_{\text {water }}\right. \\
\left.\mathrm{kg}_{\text {dry matter }}{ }^{-1}\right)\end{array}$ \\
\hline$D$ & diffusivity $\left(\mathrm{m}^{2} \mathrm{~s}^{-1}\right)$ & & \\
\hline$D_{0}$ & constant of the model that relates $D_{\text {eff }}$ with & Greek & ymbols \\
\hline & water content and temperature (Eq. (6)) & $\alpha$ & absorptivity of solar radiation \\
\hline$D_{T}$ & $\begin{array}{l}\text { constant of the model that relates } D_{\text {eff }} \text { with } \\
\text { water content and temperature (Eq. (6)) }\end{array}$ & $\Delta H_{\mathrm{c}}$ & $\begin{array}{l}\text { function of the heat sorption of water } \\
\left(\mathrm{J} \mathrm{mol}^{-1} \text {, Eq. (8)) }\right.\end{array}$ \\
\hline$D_{X}$ & $\begin{array}{l}\text { constant of the model that relates } D_{\text {eff }} \text { with } \\
\text { water content and temperature (Eq. (6)) }\end{array}$ & $\Delta H_{\mathrm{k}}$ & $\begin{array}{l}\text { function of the heat sorption of water } \\
\left(\mathrm{J} \mathrm{mol}^{-1} \text {, Eq. (9)) }\right.\end{array}$ \\
\hline$E_{\mathrm{a}}$ & activation energy $\left(\mathrm{J} \mathrm{mol}^{-1}\right)$ & $\Delta t$ & time increment (s) \\
\hline$h$ & $\begin{array}{l}\text { convective heat transfer coefficient } \\
\left(\mathrm{J} \mathrm{s} \mathrm{s}^{-1} \mathrm{~m}^{-2} \mathrm{~K}^{-1}\right)\end{array}$ & $\begin{array}{l}\varepsilon \\
\lambda\end{array}$ & $\begin{array}{l}\text { emissivity of the product } \\
\text { latent heat of vaporisation }\left(\mathrm{J} \mathrm{kg}^{-1}\right)\end{array}$ \\
\hline$k$ & $\begin{array}{l}\text { factor that corrects properties of the multi- } \\
\text { layer molecules with respect to the bulk liquid } \\
\text { (Eq. (7)) }\end{array}$ & $\begin{array}{l}\sigma \\
\text { Subscrt }\end{array}$ & $\begin{array}{l}\text { Stefan-Boltzmann constant }\left(\mathrm{J} \mathrm{s}^{-1} \mathrm{~m}^{-2} \mathrm{~K}^{-4}\right) \text {. } \\
\text { pts }\end{array}$ \\
\hline$K_{\text {ref }}$ & $\begin{array}{l}\text { rate of cellular radius change at a reference } \\
\text { temperature }\left(\mathrm{s}^{-1} \text {, Eq. (11)) }\right.\end{array}$ & $\begin{array}{l}0 \\
\mathrm{a}\end{array}$ & $\begin{array}{l}\text { initial value } \\
\text { air }\end{array}$ \\
\hline$k_{0}$ & $\begin{array}{l}\text { pre-exponential factor of the model that cor- } \\
\text { relates } k \text { to temperature (Eq. (9)) }\end{array}$ & $\begin{array}{l}\text { cel } \\
\mathrm{e}\end{array}$ & $\begin{array}{l}\text { cellular } \\
\text { equilibrium value }\end{array}$ \\
\hline & total mass of drying product $(\mathrm{kg})$ & eff & effective value \\
\hline$m_{\mathrm{dm}}$ & mass of dry matter $(\mathrm{kg})$ & $i$ & time step \\
\hline & mass of evaporated water $(\mathrm{kg})$ & $\mathrm{m}$ & value at monolayer \\
\hline & $\begin{array}{l}\text { constants of the model that relates cellular } \\
\text { radius with water content (Eq. (12)) }\end{array}$ & $\begin{array}{l}\mathrm{r} \\
\mathrm{ref}\end{array}$ & $\begin{array}{l}\text { value at the surface of the sphere } \\
\text { reference value }\end{array}$ \\
\hline
\end{tabular}

radiation is one additional and important term that should be added to the heat balance.

Significant physical changes that occur during drying of foods (such as shape and dimensions changes) should also be included in the referred models, for a complete description and control of the process. Taking into consideration the research progress in quantifying microstructural changes during drying (Ramos, Silva, Sereno, \& Aguilera, 2004) and the correlation with macroscopic shrinkage, an effort should be made to include these microstructural changes in the mass and heat transfer models.

Microstructural studies help quantifying food changes during drying and may also improve the understanding of mechanisms and changes in quality factors, namely changes in food texture (Aguilera \& Stanley,
1999). Some works approach the simulation of solar drying of fruits and vegetables, combining heat and mass transfer equations (Bala \& Woods, 1994; Fohr \& Arnaud, 1992). Phoungchandang and Woods (2000b) developed a comprehensive mathematical model applied to the solar drying of bananas. Nevertheless, the study did not include changes on physical properties, and a simple mass transfer model was applied.

The objective of this work was to develop a methodology to integrate heat and mass transfer phenomena, taking into consideration macroscopic changes (e.g. shrinkage of the food) and their correlation to changes at microscopic level (e.g. cellular shrinkage), that might occur during solar drying of grapes. A Fickian diffusion model taking into account the shrinkage effect, was considered for describing mass transport. 


\section{Modelling mass transfer}

During food drying processes there is a removal of water from the product to the environment along the time, till equilibrium is reached. According to several authors, food air-drying has in most cases a short constant-rate period, followed by a long falling-rate period (Madamba et al., 1996; Mazza \& Le Maguer, 1980; Mulet, 1994; Ratti \& Mujumdar, 1996; Yusheng \& Poulsen, 1988). This is ascribed to the fact that most foods are dense solids with low porosity, and so molecular diffusion of the liquid through the product is the limiting mechanism (Foust, Wenzel, Clump, Maus, \& Andersen, 1980). Consequently, food drying in the falling-rate period is often associated to Fick's second law. However, Fickian diffusion models are often referred as inappropriate to describe the complexity of mechanisms involved in drying processes (Jayaraman \& das Gupta, 1992; Ratti \& Mujumdar, 1996). Besides this criticism, Fickian models are still the most widely used models (Mulet, Berna, \& Rosselló, 1989; Raghavan, Tulasidas, Sablani, \& Ramaswamy, 1995).

In the case of a sphere (e.g. grapes is one typical example) where only purely radial diffusion occurs, a mass balance of a diffusing substance in an infinitesimal isotropic volume under transient conditions leads to (Crank, 1975):

$\frac{\partial X}{\partial t}=\frac{1}{r^{2}} \frac{\partial}{\partial r}\left(D r^{2} \frac{\partial X}{\partial r}\right)$

the so-called Fick's second law, descriptive of unsteady state diffusion. $X$ is the water content, $t$ is the time variable, $D$ the diffusion coefficient or diffusivity, and $r$ is the direction through which diffusion occurs.

Several analytical solutions to the previous differential equation can be obtained, since adequate initial and boundary conditions are established. If it is assumed: (i) homogeneity of the water content inside the sphere at the beginning of the drying process, (ii) water content at the surface of the product $\left(X_{\mathrm{r}}\right)$ remains constant with time and (iii) a symmetric condition at the centre of the sphere, one can write:

(i) $t=0, \quad 0 \leqslant r \leqslant r_{\mathrm{r}} \quad X=X_{0}$

(ii) $t \geqslant 0, \quad r=r_{\mathrm{r}} \quad X_{\mathrm{r}}=X_{\mathrm{e}}$

(iii) $t \geqslant 0, \quad r=0, \quad \frac{\partial X}{\partial t}=0$

where $X_{\mathrm{e}}$ is the equilibrium water content and $X_{0}$ the initial water content, usually expressed on a dry basis, and $r_{\mathrm{r}}$ is the external radius of the sphere.

An analytical solution of Fick's second law (Eq. (1)) can then be obtained for calculation of the average water content inside the food $(\bar{X})$ after a time $t$ (Crank, 1975):
$\frac{\bar{X}-X_{\mathrm{e}}}{X_{0}-X_{\mathrm{e}}}=\frac{6}{\pi^{2}} \sum_{n=1}^{\infty} \frac{1}{n^{2}} \exp \left(-n^{2} \pi^{2} \frac{D_{\mathrm{eff}} t}{r_{\mathrm{r}}^{2}}\right)$

An effective value of diffusivity should be used ( $\left.D_{\text {eff }}\right)$ to account for the non-isotropic characteristics of the medium and porosity. The previous equation expresses that the driving force of diffusion is the difference between the water content in each instant and the equilibrium water content. For sake of simplicity, in order to deduce Eq. (2), temperature is considered uniform inside the food and diffusivity assumed to be constant along the drying process. This last assumption should be carefully taken into consideration, because the water diffusivity has been found to vary considerably with the moisture of food material (Karathanos, Villalobos, \& Saravacos, 1990). On the other hand, shrinkage is an important phenomena that occurs during drying processes, so changing dimensions must be considered in Fick's diffusion law. Air conditions may also vary along drying time, thus altering equilibrium. According to the methodology of Raghavan et al. (1995) and Vázquez, Chenlo, Moreira, and Costoyas (2000), a variable diffusivity, dimensions and equilibrium values may be included in Eq. (2), if they are considered constants over only short time intervals.

\section{Dependence of difusivity on temperature and water content}

Temperature has a major effect on diffusivity. The Arrhenius law is often used to describe the relationship (Madamba et al., 1996; Mazza \& Le Maguer, 1980; Mulet et al., 1989; Newman, Price, \& Woolf, 1996; Phoungchandang \& Woods, 2000a; Yusheng \& Poulsen, 1988), sometimes expressed in terms of a finite reference temperature, $T_{\text {ref }}$ :

$D_{\text {eff }}=D_{\text {ref }} \exp \left[-\frac{E_{\mathrm{a}}}{R}\left(\frac{1}{T}-\frac{1}{T_{\text {ref }}}\right)\right]$

where $T$ is the product temperature, $R$ is the ideal gas constant, and $D_{\text {ref }}$ and $E_{\text {a }}$ are diffusion parameters, the diffusion coefficient at reference temperature and the activation energy, respectively.

As formerly mentioned, the diffusivity may also be water concentration dependent. This is particularly significant in most drying processes in which the water content changes considerably. Even so, and concerning drying of fruits and vegetables, only a small number of works take it into consideration.

When studying the concentration dependence of moisture diffusivity during drying of grapes and corn, Raghavan et al. (1995) observed that the effective diffusivity increased gradually as the drying proceeded, reaching a maximum and then decreasing more sharply till the end of the process. 
Some models have been suggested to describe the dependence of $D_{\text {eff }}$ on water content. Among the proposed models (e.g. exponential, power-law and gamma functions), the exponential expressions are the most used ones. Vázquez et al. (2000) assumed the following model to describe the dependence of $D_{\text {eff }}$ on water content, for drying of grapes:

$D_{\text {eff }}=\exp \left(a+b \bar{X}+c \bar{X}^{2}\right)$

where $a, b$, and $c$ are model parameters.

Mulet et al. (1989) considered effective diffusivity to be simultaneously dependent on water content and temperature, as follows:

$D_{\text {eff }}=\exp (d+e / T+f \bar{X})$

in which $d, e$ and $f$ are parameters.

A similar model was presented by Maroulis, Kiranoudis, and Marinos-Kouris (1995):

$D_{\text {eff }}=D_{0} \exp \left(-D_{T} / T\right) \exp \left(-D_{X} / \bar{X}\right)$

where $D_{0}, D_{T}$ and $D_{X}$ are parameters of the model.

\section{Equilibrium water content}

The equilibrium water content corresponds to the water content of the food that is in equilibrium with the surrounding air, at certain temperature, pressure and relative humidity. There are several models that mathematically describe the equilibrium (e.g. sorption isotherms equations, that represent the equilibrium relationship between water activity, $a_{\mathrm{w}}$, and water content), being recently the Guggenheim-Anderson-deBoer model, usually referred to as the G.A.B model, the most widely applied (Brennan, 1994):

$\frac{X_{\mathrm{e}}}{X_{\mathrm{m}}}=\frac{C k a_{\mathrm{w}}}{\left(1-k a_{\mathrm{w}}\right)\left(1-k a_{\mathrm{w}}+C k a_{\mathrm{w}}\right)}$

where $X_{\mathrm{m}}$ is the water content corresponding to the monolayer value, $C$ is the Guggenheim constant and $k$ is a factor correcting properties of the multilayer molecules with respect to the bulk liquid (Bizot, 1983). At equilibrium, $a_{\mathrm{w}}$ is equal to the relative humidity of the surrounding atmosphere. The parameters $C$ and $k$ are related to temperature as follows:

$C=C_{0} \exp \left(\frac{\Delta H_{\mathrm{c}}}{R T}\right)$

$k=k_{0} \exp \left(\frac{\Delta H_{\mathrm{k}}}{R T}\right)$

where $C_{0}$ and $k_{0}$ are constants, and $\Delta H_{\mathrm{c}}$ and $\Delta H_{\mathrm{k}}$ are functions of the heat sorption of water.

The equilibrium value can be estimated under temperature-varying conditions, by combining Eqs. (7)-(9). Tsami, Marinos-Kouris, and Maroulis (1990) determined moisture sorption isotherms for several fruits (e.g. grapes, currants, figs, prunes and apricots), using the GAB model in the fit to experimental drying data at several temperatures. Estimates of the parameters can be found in their work.

\section{Modelling heat transfer}

Heat transfer plays an important role in drying processes. In the case of direct solar drying, one additional term should be added to the global energy balance, since the solar energy absorbed by the product is relevant.

In direct solar dryers, foodstuffs are dried in a chamber covered with a transparent material. Solar radiation acting on a covered solar dryer originates a 'greenhouse' type effect (Brennan, 1994). Solar radiation penetrates the dryer transparent cover, almost all being transmitted to the foodstuff inside the chamber, which is heated. On the other hand, the radiation energy emitted by the heated foodstuff cannot 'escape' the dryer (Holman, 1986). A global energy balance to a solar dryer can be written in the form:

$\frac{\mathrm{d}\left(m C_{\mathrm{p}} T\right)}{\mathrm{d} t}=\alpha A_{\mathrm{p}} q_{\mathrm{s}}-h A_{\mathrm{s}}\left(T-T_{\mathrm{a}}\right)-\frac{\mathrm{d}\left(\lambda m_{\mathrm{w}}\right)}{\mathrm{d} t}-A \varepsilon \sigma\left(T^{4}-T_{\mathrm{a}}^{4}\right)$

where $m$ is the total mass of the dried product, $A_{\mathrm{p}}$ the projected area, $A_{\mathrm{s}}$ the surface area of the product available to heat transfer, $T_{\mathrm{a}}$ the air temperature and $m_{\mathrm{w}}$ is the mass of evaporated water. $C_{\mathrm{p}}$ is the specific heat capacity of the dried product, $\lambda$ the latent heat of vaporisation and $\mathrm{h}$ the convective heat transfer coefficient. The incident solar energy is denoted by $q_{\mathrm{s}}, \alpha$ is the absorptivity of solar radiation, $\varepsilon$ is the emissivity of the product and $\sigma$ the Stefan-Boltzmann constant.

The left term of the former equation corresponds to the rate of energy gained by the dried product. The terms in the right-hand side are the absorbed radiant energy, the convective heat loss, the evaporative heat loss and the radiation heat loss, respectively.

The equation may be numerically solved by a finite differences method. Nevertheless, some drawbacks emerge: the radiant solar energy must be obtained from meteorological conditions, and there is a lack of data on radiation properties of foods (Ratti \& Mujumdar, 1996). When the heat transfer model is combined with the mass transfer model (Eq. (2) is one example), additional difficulties arise. Besides the dependence on temperature, thermal properties of foods (e.g. $C_{\mathrm{p}}$ ) are also related to their chemical and physical composition, being strongly dependent on water content. Sweat (1986) compiled several empirical equations describing those relationships. Most of the research on thermal properties of foods is related to freezing and refrigeration studies 
(Miles, van Beek, \& Veerkamp, 1983), limiting their application to drying conditions.

The convective heat transfer coefficients may be estimated on the basis of correlations with dimensionless numbers (Holman, 1986).

\section{Shrinkage phenomenon}

Shrinkage is the reduction of the size of a product (macroscopic phenomenon), which is a reflection of the reduction of its cellular dimensions (microscopic phenomena). In drying processes, this is a result of water loss from the product.

Frequently neglected when developing drying models, shrinkage has been recognised as an important phenomenon that should not be mistreated (Ratti \& Mujumdar, 1996). The majority of studies consider constant size of the product, and consequently the accuracy of the models applied could be seriously affected (e.g. the mass transfer model is directly dependent on the size of the medium).

\section{Macroscopic shrinkage}

Macroscopic shrinkage is commonly referred to as the ratio of the volume of the product $(V)$ to the initial volume $\left(V_{0}\right)$. The most common techniques used to determine experimentally macroscopic shrinkage are direct measurement of the dimensions of the product with a calliper, or by picnometric volume measurements in organic solutions (Zogzas, Maroulis, \& Marinos-Kouris, 1994; Moreira, Figueiredo, \& Sereno, 2000). Photographing the product (Suzuki, Kubota, Hasegawa, \& Hosaka, 1976; Prado, Alonso, \& Park, 2000) with subsequent image analysis (e.g. quantifying radius, areas, volumes, etc.) have been more recently applied, due to easy access to modern image analysis techniques. The precision of the measurements increases if pictures are taken from a large number of different angles of the product. This procedure was applied to the study of macroscopic shrinkage during drying of grapes. In Fig. 1 it is shown an example of a pictures sequence for a total of 15 days of drying, obtained in a pilot convective dryer (Ramos, 2003), where temperature and humidity conditions were

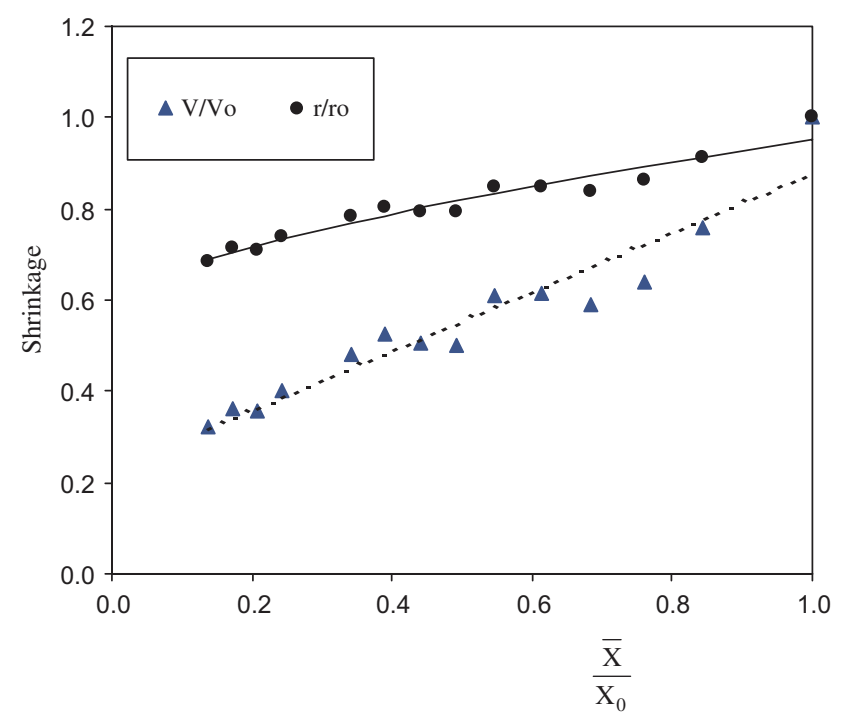

Fig. 2. Variation of macroscopic shrinkage with water content (Ramos, 2003). - - - $\frac{V}{V_{0}}=0.224+0.670\left(\frac{\bar{X}}{X_{0}}\right) \quad R^{2}=0.926 ;-$ $\frac{r_{r}}{r_{0}}=\sqrt[3]{0.224+0.670\left(\frac{\bar{X}}{X_{0}}\right)} \quad R^{2}=0.926$

controlled in such a way that they were similar to the ones observed in a solar dryer. The image sequences were treated, which allowed obtaining the volume of the grapes (and obviously an equivalent radius, considering grapes as spheres) as a function of water content. In Fig. 2 it is represented the results and the fits of a linear model (for variation of $V / V_{0}$ with $\bar{X}$ ) and a cubic square root model (for variation of $r_{\mathrm{r}} / r_{0}$ with $\bar{X}$ ) to the data (Ramos, 2003). The radius of the grapes decreased upon to $30 \%$ till the end of the process. This significant variation stresses the need to include shrinkage in mass transfer models.

Several authors also modelled empirically the dependence of shrinkage of dried fruits and vegetables on water content, also assuming linear relationships (Krokida \& Maroulis, 1997; Moreira et al., 2000; Simal, Mulet, Catalá, Cañellas, \& Rosselló, 1996; Vázquez et al., 2000; Zogzas et al., 1994). Lozano, Rotstein, and Urbicain (1983) developed mathematical models to express the dependence of shrinkage on water content, based on fundamental considerations. An extensive review on empirical and fundamental models is presented by Mayor and Sereno (2004).
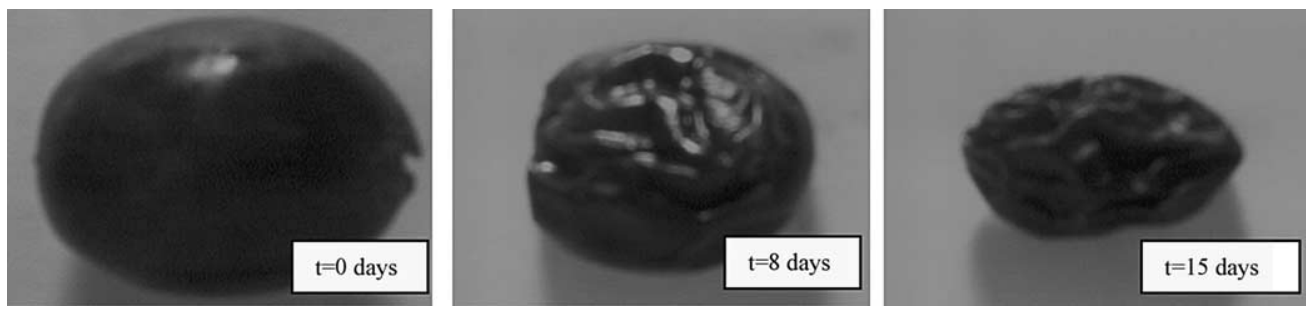

Fig. 1. Macroscopic shrinkage of grapes during drying (Ramos, 2003). 


\section{Microscopic shrinkage}

Shrinkage during drying is a reflection of microstructural changes that occur in cells. In pioneer studies, Reeve (1943) and Crafts (1944) observed shrinkage at microscopic level, for several dehydrated fruits and vegetables.

Loss of water with consequent damage and disruption of cellular walls, and even collapse of the cellular tissue, originates shrinkage. According to Mattea, Urbicain, and Rotstein (1989), a decrease in water content also causes loss of turgor pressure, which is related to rheological properties and texture of tissues. Loss of water related to drying is mainly from the vacuolar compartment, and less from the cytoplasm and cellular walls (Hills \& Remigereau, 1997). Nowadays, geometric cellular changes may be quantified by image analysis (Aguilera \& Stanley, 1999).

Ramos et al. (2004) quantified microstructural changes during drying of grape tissue, analysing parameters related to cellular dimensions and cellular shape: area, perimeter, Feret diameter, major and minor axis length, elongation, roundness and compactness. Pictures of overall cellular shrinkage during drying (Fig. 3) were treated by image analysis. A first-order model was used to describe the variation of the cellular dimension factors along the time. The temperature effect was included in the rate constant estimation, assuming an Arrhenius tendency. As an example, for the cellular radius $\left(r_{\text {cel }}\right)$ change:

$\frac{r_{\text {cel }}}{r_{\text {ceel }}}=\exp \left\{-K_{\text {ref }} \exp \left[-\frac{E_{\mathrm{a}}}{R}\left(\frac{1}{T}-\frac{1}{T_{\text {ref }}}\right)\right] t\right\}$

where $r_{0 \text { cel }}$ is the initial cellular radius, $K_{\text {ref }}$ the rate of change at a reference temperature and $E_{\mathrm{a}}$ the activation energy.

However, to use this information in mass and heat transfer models, one should be able to obtain microscopic shrinkage as a function of water content. If microscopic shrinkage reflects perfectly macroscopic changes, the dimensions reduction will be similar. In the case of being different, a correlation between both can be obtained. Hence, one possible relationship between cellular radius and water content would be of the form: $\frac{r_{\mathrm{cel}}}{r_{0 \mathrm{cel}}}=\sqrt[3]{p+q\left(\frac{\bar{X}}{X_{0}}\right)}$

where $p$ and $q$ are constants.

Correlating micro and macroscopic shrinkage of dried foods needs further research effort, being an attractive area with multiple fields of involvement.

\section{Integrated model for solar drying simulation}

After all previous considerations concerning mass and heat transfer, and the shrinkage phenomena, the final goal was to combine them all in one global and integrated model. The steps involved in solving this model are presented in the flowsheet of Fig. 4.

It is necessary an input of data related to mass transfer phenomenon (e.g. parameters of the expressions that relate diffusivity with $\bar{X}$ and $T$, and parameters of sorption isotherms) and shrinkage (relationship between product radius and $\bar{X}$ ). Heat transfer coefficients, thermal properties or their relations to product water content, data of air conditions inside the solar dryer and incident radiation should also be available.

Once having initial estimates of water content and temperature of the product, the following is to determine water content at next time step, using appropriate analytical solutions of Fick's second law (Eq. (2)). The temperature of the product can be estimated on the basis of Eq. (10), which can be re-written in finite differences form:

$$
\begin{aligned}
T_{i+1}=[ & \alpha A_{\mathrm{p}} q_{\mathrm{s}}-h A_{\mathrm{s}}\left(T_{i}-T_{\mathrm{a}}\right)-\frac{\lambda\left(\bar{X}_{i}-\bar{X}_{i+1}\right) m_{\mathrm{dm}}}{\Delta t} \\
& \left.-A_{\mathrm{s}} \varepsilon \sigma\left(T_{i}^{4}-T_{\mathrm{a}}^{4}\right)\right] \frac{\Delta t}{m_{\mathrm{dm}}\left(1+\bar{X}_{i}\right) C_{\mathrm{p}}}+T_{i}
\end{aligned}
$$

where $i$ is the time step, $m_{\mathrm{dm}}$ is the mass of dry matter $(\mathrm{kg})$ and $\Delta t$ is the time increment. This temperature is used again in calculation of $\bar{X}$ in the next time step, and this cycle of calculations proceeds till equilibrium is reached.
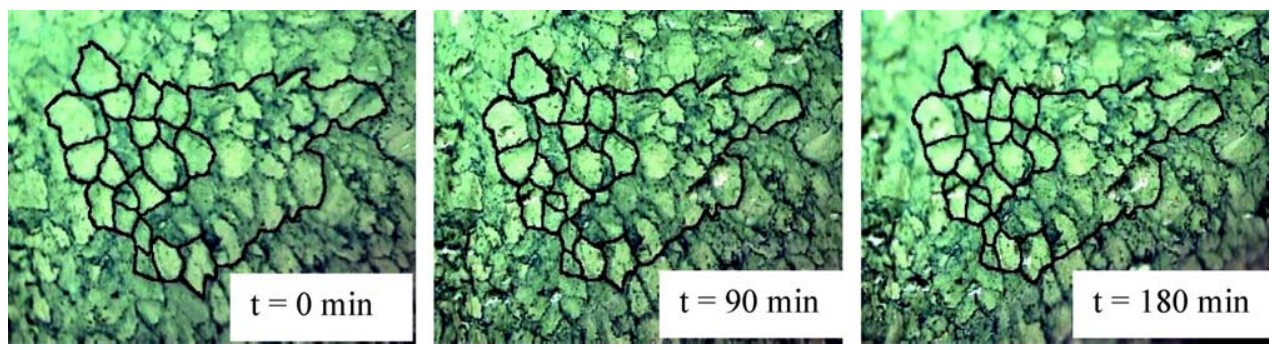

Fig. 3. Microscopic shrinkage of grapes during drying (Ramos et al., 2004). 


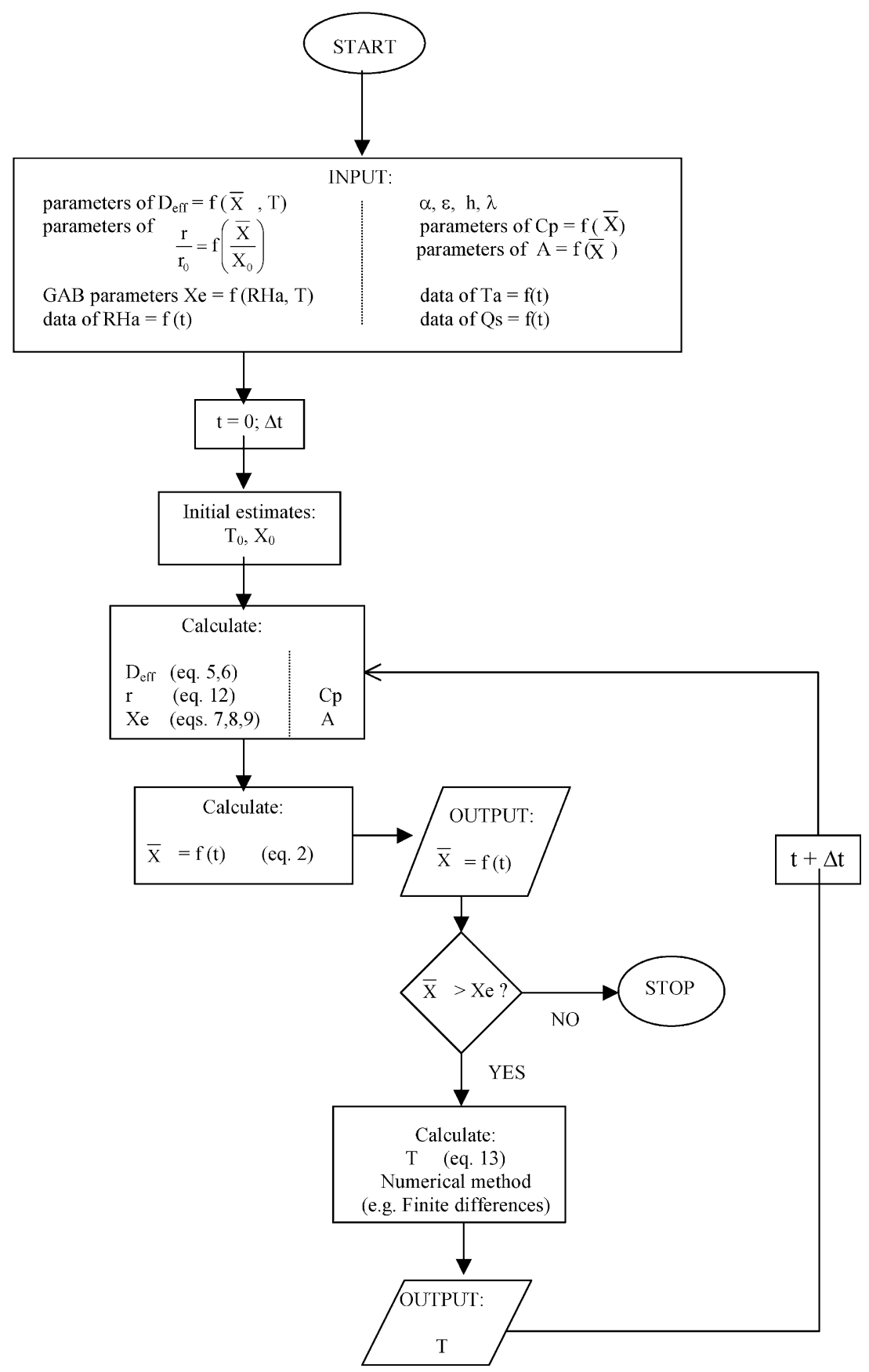

Fig. 4. Flowsheet for simulation of solar drying curves.

If a correlation between micro and macroscopic shrinkage is attained, microstructural changes can be included in the integrated model. This would allow to study and simulate the effects of different drying and/ or storage conditions on dried products microstructure. If microstructure is related to a quality attribute or to a final sensory property, a complete integrated methodology would be achieved. This would contribute to relate solar drying conditions and food quality, and further optimisation.

\section{Critical analysis}

To approach the mathematical modelling and simulation of solar drying of foods, the integration of heat, mass and shrinkage phenomena is required. Regarding heat transfer, there is lack of information on thermal properties of foods, specially concerning radiative properties. Due to the great changes of water content during drying, efforts should be taken for the analysis of the dependence of thermal properties of foods on water 
content. The dependence of mass transfer parameters on water content is also important and should not be forgotten.

Taking into consideration the research progress in quantifying microstructural changes during drying and relationships with macroscopic shrinkage, an effort should be made to include these microstructural changes in the mass and heat transfer models. Correlations of changes that occur at microscopic level with the ones macroscopically observed is one interesting area that still offers a lot of features to be exploited.

\section{Acknowledgment}

The author Inês N. Ramos would like to acknowledge PRAXIS XXI PhD grant no. 18543/98 to Fundação para a Ciência e a Tecnologia, Portugal and CYTED XI.13 project: "Relaciones Estructura-Propriedad en la Deshidratacion y Almacenaje de Alimentos Dehidratados".

\section{References}

Aguilera, J. M., \& Stanley, D. W. (1999). Microstructural principles of food processing and engineering (second ed.). Gaithersburg: Aspen Publishers.

Bala, B. K., \& Woods, J. L. (1994). Simulation of the indirect natural convection solar drying of rough rice. Solar Energy, 53(3), 259-266.

Bizot, H. (1983). Using the 'G.A.B.' model to construct sorption isotherms. In R. Jowitt, F. Escher, B. Hallström, H. Meffert, W. Spiess, \& G. Vos (Eds.), Physical properties of foods (pp. 43-54). Essex: Applied Science Publishers.

Bolin, H. R., \& Salunkhe, D. K. (1982). Food dehydration by solar energy. CRC-Critical Reviews in Food Science and Nutrition, 16(4), 327-354.

Brennan, J. G. (1994). Food dehydration: A dictionary and guide. Oxford: Butterworth-Heinemann.

Crafts, A. S. (1944). Cellular changes in certain fruits and vegetables during blanching and dehydration. Food Research, 9, 442-452.

Crank, J. (1975). The mathematics of diffusion (second ed.). Oxford: Clarendon Press

Fohr, J. P., \& Arnaud, G. (1992). Grape drying: from sample behaviour to the drier project. Drying Technology, 10(2), 445-465.

Foust, A. S., Wenzel, L. A., Clump, C. W., Maus, L., \& Andersen, L. B. (1980). Principles of unit operations (second ed.). Singapore: John Wiley \& Sons.

Hills, B. P., \& Remigereau, B. (1997). NMR studies of changes in subcellular water compartmentation in parenchyma apple tissue during drying and freezing. International Journal of Food Science and Technology, 32, 51-61.

Holman, J. P. (1986). Heat transfer (sixth ed.). Singapore: McGrawHill.

Jayaraman, K. S., \& das Gupta, D. K. (1992). Dehydration of fruits and vegetables - recent developments in principles and techniques. Drying Technology, 10(1), 1-50.

Karathanos, V. T., Villalobos, G., \& Saravacos, G. D. (1990). Comparison of two methods of estimation of the effective moisture diffusivity from drying data. Journal of Food Science, 55(1), 218-223, 231.
Krokida, M. K., \& Maroulis, Z. B. (1997). Effect of drying method on shrinkage and porosity. Drying Technology, 15(10), 2441-2458.

Lozano, J. E., Rotstein, E., \& Urbicain, M. J. (1983). Shrinkage, porosity and bulk density of foodstuffs at changing moisture contents. Journal of Food Science, 48, 1497-1502, p. 1553.

Madamba, P. S., Driscoll, R. H., \& Buckle, K. A. (1996). The thin layer drying characteristics of garlic slices. Journal of Food Engineering, 29, 75-97.

Maroulis, Z. B., Kiranoudis, C. T., \& Marinos-Kouris, D. (1995). Heat and mass transfer modeling in air drying of foods. Journal of Food Engineering, 26, 113-130.

Mattea, M., Urbicain, M. J., \& Rotstein, E. (1989). Computer model of shrinkage and deformation of cellular tissue during dehydration. Chemical Engineering Science, 44, 2853-2859.

Mayor, L., \& Sereno, A. M. (2004). Modelling shrinkage during convective drying of food materials: a review. Journal of Food Engineering, 61, 373-386.

Mazza, G., \& Le Maguer, M. (1980). Dehydration of onion: some theoretical and practical considerations. Journal of Food Technology, 15, 181-194.

Miles, C. A., van Beek, G., \& Veerkamp, C. H. (1983). Calculation of thermophysical properties of foods. In R. Jowitt, F. Escher, B. Hallström, H. Meffert, W. Spiess, \& G. Vos (Eds.), Physical properties of foods (pp. 269-312). Essex: Applied Science Publishers.

Moreira, R., Figueiredo, A., \& Sereno, A. (2000). Shrinkage of apple disks during drying by warm air convection and freeze drying. Drying Technology, 18(1\&2), 279-294.

Mühlbauer, W., \& Esper, A. (1999). Solar energy. In T. Jungbluth, R. M. Peart, A. Ramdani, \& O. Kitani (Eds.), CIGR handbook of agriculture engineering: Energy and biomass engineering. ASAE.

Mulet, A. (1994). Drying modelling and water diffusivity in carrots and potatoes. Journal of Food Engineering, 22, 329-348.

Mulet, A., Berna, A., \& Rosselló, C. (1989). Drying of carrots. I. Drying models. Drying Technology, 7(3), 537-557.

Newman, G. M., Price, W. E., \& Woolf, L. A. (1996). Factors influencing the drying of prunes. 1 . Effects of temperature upon the kinetics of moisture loss during drying.

Phoungchandang, S., \& Woods, J. L. (2000a). Moisture diffusion and desorption isotherms for banana. Journal of Food Science, 65(4), 651-657.

Phoungchandang, S., \& Woods, J. L. (2000b). Solar drying of bananas: mathematical model, laboratory simulation, and field data compared. Journal of Food Science, 65(6), 990-996.

Prado, M. E. T., Alonso, L. F. T., \& Park, K. J. (2000). Shrinkage of dates (Phoenix Dactilyfera L.) during drying. Drying Technology., 18(1\&2), 295-310.

Raghavan, G. S. V., Tulasidas, T. N., Sablani, S. S., \& Ramaswamy, H. S. (1995). A method of determination of concentration dependent effective moisture diffusivity. Drying Technology, 13(57), 1477-1488.

Ramos, I. N. (2003). A new methodology for optimisation of fruit solar drying. Progress report. Internal document of Escola Superior de Biotecnologia-Universidade Católica Portuguesa.

Ramos, I. N., Silva, C. L. M., Sereno, A. M., \& Aguilera, J. M. (2004). Quantification of microstructural changes during first stage air drying of grape tissue. Journal of Food Engineering, 62, 159-164.

Ratti, C., \& Mujumdar, A. S. (1996). Drying of fruits. In L. P. Somogyi, H. S. Ramaswamy, \& Y. H. Hui (Eds.). Processing fruits: Science and technology (Vol. 1, pp. 185-220). Lancaster: Technomic Publishing.

Reeve, R. M. A. (1943). Microscopic study of the physical changes in carrots and potatoes during dehydration. Food Research, 8, 128-136.

Simal, S., Mulet, A., Catalá, P. J., Cañellas, J., \& Rosselló, C. (1996). Moving boundary model for simulating moisture movement in grapes. Journal of Food Science, 6(1), 157-160. 
Suzuki, K., Kubota, K., Hasegawa, T., \& Hosaka, H. (1976). Shrinkage in dehydration of root vegetables. Journal of Food Science, 41, 1189-1194.

Sweat, V. E. (1986). Thermal properties of foods. In M. A. Rao \& S. S. H. Rizvi (Eds.), Engineering properties of foods (pp. 49-87). New York: Marcel Dekker.

Tsami, E., Marinos-Kouris, D., \& Maroulis, Z. B. (1990). Water sorption isotherms of raisins, currants, figs, prunes and apricots. Journal of Food Science, 55(6), 1594-1625.
Vázquez, G., Chenlo, F., Moreira, R., \& Costoyas, A. (2000). Effects of various treatments on the drying kinetics of Muscatel grapes. Drying Technology, 18(9), 2131-2144.

Yusheng, Z., \& Poulsen, K. P. (1988). Diffusion in potato drying. Journal of Food Engineering, 7, 249-262.

Zogzas, N. P., Maroulis, Z. B., \& Marinos-Kouris, D. (1994). Densities, shrinkage and porosity of some vegetables during air drying. Drying Technology, 12(7), 1653-1666. 